\title{
Estudos de Reaeração com Velocimetria por Imagens de Partículas - Sistema S-PIV-3D
}

\section{Rearation Studies with Particle Image Velocimetry - S-PIV-3D System}

\author{
Marcos Rogério Szeliga \\ Engenheiro Civil. Mestre em Engenharia Hidráulica pela Universidade Federal do Paraná (UFPR). Doutor em Hidráulica e Saneamento pela Universidade de \\ São Paulo (USP). Pós-Doutorado pela USP. Professor Adjunto da Universidade Estadual de Ponta Grossa (UEPG) \\ Woodrow Nelson Lopes Roma \\ Engenheiro Mecânico. Doutor em Hidráulica e Saneamento pela USP. Pós-Doutorado pela Universidade de Minnesota, EUA. Professor Titular da Escola de \\ Engenharia de São Carlos da USP
}

\begin{abstract}
Resumo
Particle Image Velocimetry (PIV) é uma técnica recente de medição não-intrusiva de campos de velocidades em escoamentos. Neste trabalho, foi desenvolvido um equipamento de medição com características similares aos convencionais, porém com algumas características exclusivas, como o método óptico de aquisição de imagens e a calibração de coordenadas, que resultaram na utilização de uma única câmera convencional para obtenção de imagens e dados tridimensionais em escoamentos de baixa turbulência, proporcionando significativa economia na implantação. Foi desenvolvido um software específico e os resultados consistem em campos de velocidades tridimensionais. A aplicação destinou-se à medição de velocidades na superfície do escoamento em um tanque de grades oscilantes de forma a correlacionar a turbulência superficial com a capacidade de reaeração dos corpos da água.
\end{abstract}

Palavras-chave: PIV, velocimetria por imagens de partículas, turbulência, métodos ópticos de medição, reaeração.

\section{Abstract}

Particle Image Velocimetry (PIV) is a recent technique of flow measurement labeled as a non-intrusive methodology. The system developed in this paper used principles similar to conventional systems including some exclusive characteristics as the optical method of image acquisition and the calibration process of the coordinate system. The measurement system, resulted from these characteristics, uses a single conventional digital video camera to obtain three-dimensional data in low turbulence flow, which provided significant economy in the system implantation. A specific software was developed and the results consist of fields of three-dimensional velocities obtained from the digital video file. The application was destined to the measurement of velocities on the flow surface in a tank of oscillating grids in order to correlate the surface turbulence with the rearation capacity of the bodies of water.

Keywords: PIV, particle image velocimetry, turbulence, optical measurement methods, rearation.

\section{Introdução}

O processo natural de reaeração de corpos de água receptores de despejos de esgotos envolve a transferência de massa superficial por meio da qual a demanda por oxigênio, resultante da ação bacteriológica sobre a matéria orgânica biodegradável, pode ser suprida dependendo da intensidade com que o fenômeno de transferência de oxigênio ocorre através da superfície do corpo receptor. Quantitativamente, a transferência de massa superficial pode ser definida por meio de equações de transporte que utilizam o coeficiente de transferência gasosa, $\mathrm{K}_{\mathrm{L}}$, e mais especificamente, a transferência de oxigênio, através do coeficiente de reaeração, $\mathrm{K}_{2}$. Esses coeficientes são influenciados por diversos fatores, como temperatura, pressão, vento, umidade do ar e especialmente a turbulência na superfície. A turbulência desempenha um importante papel no processo de reaeração, seja pela inserção de componentes advectivas na transferência, pela ampliação da superfície de contato entre a água e a atmosfera ou pela renovação da camada superficial. O estudo da intensidade turbulenta pode levar à consecução de modelos que auxiliem o processo de gerenciamento de bacias hidrográficas estipulando condições mínimas de tratamento prévio em descargas de esgotos, embasamentos para Estudos de Impactos Ambientais e demais procedimentos relacionados ao monitoramento da qualidade da água. Após a determinação do coeficiente de reaeração $\mathrm{K}_{2}$ para uma dada situação de um curso d'água, é possível 
estimar o tempo necessário para que determinada carga produtora de demanda de oxigênio tenha seus níveis reduzidos a condições toleráveis, bem como, o tempo de atuação da carga e a extensão do curso d'água em que a carga produz efeitos não-aceitáveis (SZELIGA; ROMA, 2004).

As medições de velocidades na superfície de escoamentos livres conduzem a parâmetros de avaliação da intensidade de turbulência. Entre estes parâmetros, encontra-se a componente vertical da velocidade do escoamento, que pode traduzir a intensidade turbulenta em termos de sua influência na transferência de massa e levar a uma correlação para determinação da capacidade de reaeração do corpo líquido (SZELIGA; ROMA, 2004).

Neste trabalho, foram realizados experimentos quanto à geração de turbulência em corpo líquido utilizando um tanque de grade oscilante que tem a finalidade de reproduzir em laboratório os níveis de turbulência encontrados nos escoamentos naturais. Foram realizadas medições de velocidades na superfície através de uma técnica não-intrusiva especialmente desenvolvida que foi intitulada "Sistema S-PIV-3D". Os resultados foram correlacionados com o coeficiente de reaeração $\mathrm{K}_{2}$ obtidos em ensaios de desoxigenação e reaeração para cada nível de turbulência operada no tanque.

Nos últimos anos, com o crescente incremento da capacidade de aquisição de imagens dos dispositivos e do processamento digital, a técnica PIV (Particle Image Velocimetry) tornou-se uma das mais populares ferramentas para medição de velocidade numa variada gama de aplicações (JANSEN, 2004). A técnica conduz à obtenção de campos de velocidades em escoamentos a partir do processamento das imagens de partículas traçadoras adicionadas ao escoamento e iluminadas por um feixe laser em lâmina.

O desenvolvimento de tecnologia baseada nos sistemas PIV foi proposto e desenvolvido num projeto de pesquisa intitulado "Velocimetria de Partículas por Visão Estereoscópica - Sistema S-PIV3D". Este projeto envolveu o estudo e a aplicação de alternativas na geração, captura e processamento das imagens, incluindo o desenvolvimento do software próprio de calibração e processamento de imagens; o método óptico de aquisição de imagens que consiste num estereoscópio ajustável que, em conjunto com uma única câmera digital convencional, viabilizou a aquisição de imagens para a definição tridimensional do campo a ser medido; a metodologia e dispositivos de calibração e a iluminação por módulos lasers industriais. Para a aplicação no tanque de grade oscilante e correlação com a reaeração, foi implantado no software de controle um módulo de resultados específicos com relação às velocidades verticais do escoamento.

O sistema S-PIV-3D envolve, em uma primeira etapa, a calibração do sistema, na qual com o auxílio de um grid pré-definido e fotos de calibração, obtêm-se os parâmetros de uma função de transformação dos dados obtidos das imagens para um sistema real de coordenadas tridimensionais. A partir da aplicação da função de transformação, são obtidas coordenadas reais, definindo o posicionamento das partículas e possibilitando o cálculo dos deslocamentos reais. Outra etapa envolve o processamento de imagens e o algoritmo de correlações cruzadas normalizadas para obter o deslocamento das partículas entre imagens sucessivas. Os deslocamentos divididos pela unidade de tempo de aquisição lançados nas células (áreas de interrogação) de uma malha produzida sobre a região de estudo conduzem aos vetores-velocidade.

A aquisição de dados tridimensionais implica a necessidade de uma tomada de cena sob, no mínimo, dois pontos de vista distintos simultaneamente. Para estudos de campos tridimensionais, os sistemas PIV convencionais empregam duas ou mais câmeras de aquisição eletronicamente sincronizadas. O sistema desenvolvido neste projeto utilizou um dispositivo óptico para eliminar a necessidade da segunda câmera, obtendo imagens oriundas de pontos de vista distintos por meio de um estereoscópio. Este estereoscópio foi desenhado de forma a flexibilizar o posicionamento dos dispositivos de aquisição e se adaptar aos requisitos impostos pelo sistema de medição. A imagem resultante consiste em dois campos que compartilham cada quadro, com uma aquisição naturalmente simultânea. Foi utilizada uma câmera de alta definição com resolução de 1.920 colunas e 1.080 linhas.

Os ensaios para a obtenção de velocidades verticais na superfície consistiram na instalação do sistema sobre o tanque de grade oscilante com tomadas de cenas para diferentes velocidades de oscilação da grade. O software S-PIV-3D fornece gráficos interativos de resultados e dados numéricos que proporcionam a análise e o diagnóstico do comportamento do escoamento. Para esta aplicação, os resultados foram organizados em gráficos de visualização expandida e gráficos de médias dos módulos dos vetores-velocidade. O resultado obtido desta metodologia apresenta a correlação das médias dos módulos de velocidades verticais com os coeficientes de reaeração. Através desse método, pode-se prever a capacidade de autodepuração de corpos d'água quando forem obtidas as velocidades nas superfícies destes corpos e for aplicada a correlação para, então, obtermos os respectivos coeficientes de reaeração..Entretanto, a atual pesquisa restringe a aplicação ao ambiente laboratorial. Aplicações em campo requerem desenvolvimento de instalações e metodologias especiais e são objetos de estudo em outras pesquisas futuras e em andamento.

\section{Revisão bibliográfica}

Os pioneiros no uso de sistemas de geração de turbulência por grades oscilantes foram Rouse e Dodu (1955), que pesquisaram o processo turbulento de mistura utilizando uma interface líquidolíquido. Thompson e Turner (1975) utilizaram o sistema de grades oscilantes no estudo da estrutura turbulenta.

Os estudos referentes à reaeração, na Escola de Engenharia de São Carlos da Universidade de São Paulo (EESC-USP), vêm 
se desenvolvendo há décadas. Os primeiros estudos foram iniciados por Giorgetti e Giansanti (1983) que avaliaram o desgaste de sondas solúveis em função da intensidade turbulenta próxima à superfície em águas correntes, correlacionando os resultados com o coeficiente de reaeração. Roma (1988) introduziu a ideia de se obter o nível de agitação da superfície livre de um escoamento através da relação entre a agitação e o sinal captado por um fotoreceptor imerso intitulado "Sonda Óptica", iniciando as medições por meio de métodos ópticos. Szeliga e Roma (2004), através de um sistema por iluminação pontual a laser e técnicas de Visão Computacional, obtiveram velocidades localizadas em um ponto da superfície e relacionaram graficamente essas velocidades com o coeficiente de reaeração $\mathrm{K}_{2}$. Righetto (2008) utilizou um tanque de grade oscilante para realizar ensaios de deaeração e reaeração, obtendo o coeficiente $\mathrm{K}_{2}$.

As primeiras aplicações comerciais de sistemas de medição baseados na Velocimetria por Imagens de Partículas datam de 1997. Conforme Raffel et al. (2007), na maioria das aplicações, partículas traçadoras, que devem ser adicionadas ao escoamento, são iluminadas e seu posicionamento é registrado entre curtos intervalos de tempo. Normalmente, a iluminação é feita por meio de emissão laser e os registros de imagens, através de câmeras convencionais ou digitais, podem ocorrer em um único frame ou numa sequência de frames. O intervalo de tempo de exposição na aquisição da imagem deve ser pequeno o suficiente para congelar o movimento das partículas e evitar o efeito "blurring" - excesso de exposição em escoamentos rápidos. Para a avaliação do campo de velocidades, um par de imagens PIV é dividido em pequenas subáreas chamadas de "áreas de interrogação". O vetor 'deslocamento local' para as imagens das partículas é determinado para cada área de interrogação por meio de métodos estatísticos - autocorrelação ou correlação cruzada. Assume-se que todas as partículas dentro de uma área de interrogação se movam de forma relativamente homogênea entre as áreas de interrogação da primeira e segunda imagem (RAFFEL et al, 2007).

PIV é uma técnica de medição indireta de velocidades, isto é, as velocidades medidas são das partículas em suspensão e não do fluido em movimento propriamente dito. Para escoamentos com um Número de Reynolds bastante baixo, uma estimativa da discrepância de velocidades entre o fluido e as partículas num campo uniformemente acelerado pode ser obtido pela Equação 1, derivada a partir da Lei de Arraste de Stokes:

$\Delta U=U_{P}-U=d_{P}^{2} \frac{\rho_{P}-\rho}{18 \mu} a$ Equação 1

$\mathrm{Na}$ qual:

$\mathrm{U}_{\mathrm{P}:}$ velocidade da partícula;

U: velocidade do fluido;

$\mathrm{d}_{\mathrm{p} .}$ diâmetro da partícula;

$\rho_{\mathrm{P}}$ e $\rho$ : massa específica da partícula e do fluido, respectivamente; $\mu$ : viscosidade dinâmica do fluido;

a: aceleração do campo (RAFFEL et al, 2007).

Percebe-se que a utilização de partículas de reduzido diâmetro e densidade próxima da densidade do fluido pode minimizar a defasagem de velocidades. Em campos com velocidades uniformes, esperase um acompanhamento ideal das partículas com o movimento do fluido.

Com relação à calibração do sistema Petracci et al (2003) demonstraram a necessidade de um alinhamento cuidadoso entre o alvo de calibração e a lâmina de iluminação. Com o intuito de estabelecer a popularização da técnica PIV, Okamoto et al (2000) propuseram o PIVSTD Project, no qual dispuseram imagens padronizadas para verificação da capacidade de reconhecimento e acurácia dos sistemas PIV.

A técnica PIV vem se desenvolvendo substancialmente a nível mundial, sendo que já existem sistemas amplamente consolidados. Urban e Mungal (2001) aplicaram a técnica PIV em túnel de vento para obtenção de campos de velocidades bidimensionais em escoamento de alta velocidade. Yang e Rockweel (2002) estudaram as interações de ondas na superfície livre com um cilindro vertical. Smith e Glazer (2002) investigaram o escoamento de jatos de ar através de orifícios empregando um sistema PIV com câmeras de alta resolução (10 MP) e exposição de $1 \mu$ s. Tao, Katz e Meneveau (2002), utilizando um sistema HPIV (Holographic Particle Image Velocimetry), obtiveram a distribuição tri-dimensional de velocidades no escoamento turbulento em um tubo de seção quadrada. Cicca et al (2002) investigaram a turbulência na camada de escoamento junto à parede de contorno sujeita a perturbações externas. Com aplicação da técnica para visualização tri-dimensional do escoamento - Stereoscopic Particle Image Velocimetry - Alkislar, Krothapalli e Lourenço (2003) investigaram escoamentos formados por jatos em regime não-permanente. Dong et al (2005) combinaram a técnica PIV com simulações numéricas para o estudo do escoamento junto à parede de um cilindro. Pu e Meng (2005) introduziram inovações na técnica HPIV com visualizações de estruturas de vórtices. Sengupta et al (2007) estudaram o escoamento incompressível em torno de um aerofólio.

Em agosto de 2009, a Universidade de Monash, Melbourne, Austrália, promoveu o Eighth International Symposium on Particle Image Velocimetry. Este simpósio sucedeu as edições dos encontros científicos realizados em Fukui, Japão, (1995 e 1997), Santa Barbara, EUA, (1999), Göettingen, Alemanha, (2001), Busan, Coreia, (2003), Pasadena, EUA (2005) e Roma, Itália (2007).

\section{Metodologia}

O sistema S-PIV-3D apresenta algumas alternativas para implantação, operação e obtenção de resultados que o torna acessível para laboratórios de demonstração das características cinemáticas do 
escoamento. O processo de aquisição de imagens utiliza um dispositivo óptico para permitir a manipulação tridimensional. Um conjunto de espelhos planos e um prisma de faces espelhadas acoplados conforme uma geometria apropriada facilita a aquisição de imagens simultâneas segundo pontos de vista distintos, o que é imprescindível para a obtenção de dados tridimensionais. Com este dispositivo óptico, um modelo de estereoscópio, é possível a utilização de uma única câmera na aquisição de imagens em estudos de campos tridimensionais. Para produção de imagens, são utilizados módulos lasers industriais. Na aplicação do tanque de grades, não se utilizou a metodologia de emissão laser por pulsos, comum nos sistemas PIV. Cada módulo produz um feixe em lâmina com abertura de $90^{\circ} \mathrm{e}$ com espessura ajustável. Os módulos são posicionados com suportes específicos que permitem ajustar a geometria da emissão em uma lâmina que contém o plano xy do sistema de coordenadas.

A Figura 1 contém a representação dos dispositivos, sendo possível observar a configuração estabelecida através do posicionamento da câmera digital diante do arranjo de espelhos que constituem o estereoscópio. Pode-se notar, em função do caminho óptico, o compartilhamento do quadro de imagem decorrente do arranjo estereoscópico. Inclui-se, ainda, a disposição para iluminação através dos módulos lasers e seus suportes de ajuste.

O processo de calibração do sistema se caracteriza pela liberdade de posicionamento dos dispositivos de aquisição e se fundamenta numa relação entre imagem obtida e objeto fotografado que se preserva durante a consecução de ensaios. Esta relação guarda fatores que englobam todas as variáveis que eventualmente poderiam influenciar a definição de valores. A calibração dispensa introdução de correções

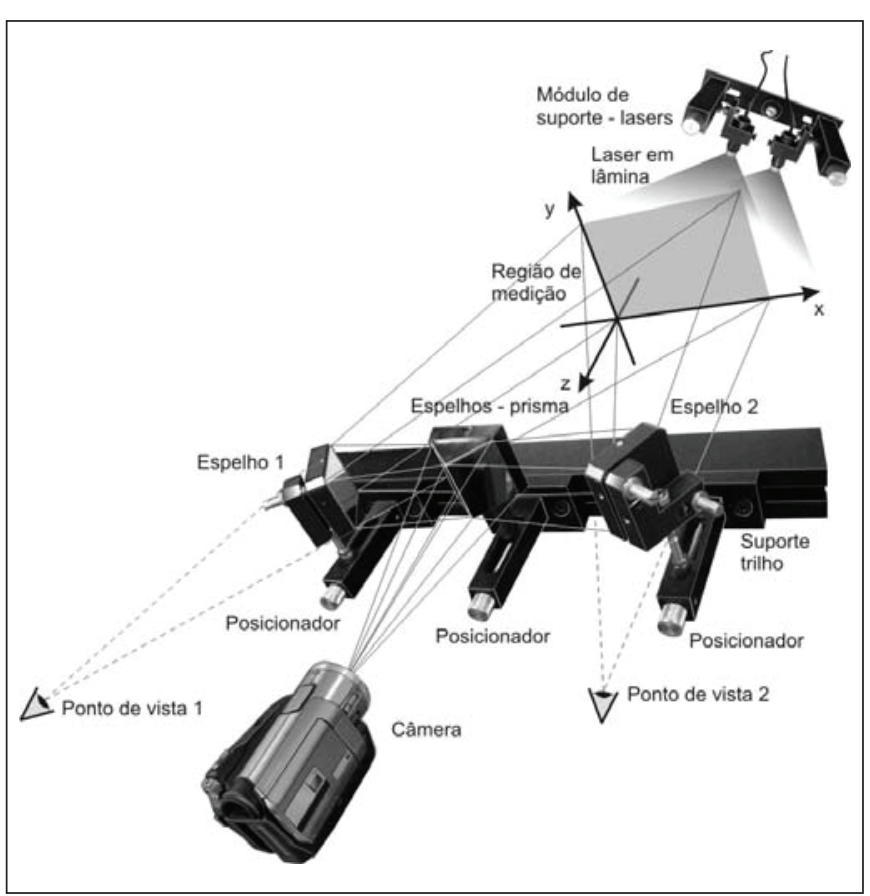

Figura 1 - Disposição dos elementos de produção e aquisição de imagens devido à refração entre meios diferentes, engloba a distorção óptica do equipamento e a perspectiva natural. A calibração compreende a aplicação de uma função de transformação ponto a ponto, isto é, existe uma solução otimizada para cada ponto da imagem que se pretende transformar para uma coordenada real. O alvo de calibração que consiste numa placa milimetricamente marcada constitui um grid quadrangular de pontos espaçados em módulos de $5 \times 5 \mathrm{~mm}$. A malha abrange uma região de 50 x $50 \mathrm{~mm}$ que define o plano xy do sistema de coordenadas real. O grid (alvo de calibração), colocado numa posição coincidente com o plano principal de medição na região de estudo do escoamento, é sustentado por um conjunto de suportes com mobilidade para as finalidades da configuração geométrica do sistema de coordenadas. Os procedimentos de calibração consistem em posicionar o alvo neste plano principal, obter uma foto estática com a mesma definição e posição de tomada de cena, que serão operadas no ensaio de tomadas de medidas, mover paralelamente o alvo de calibração para uma posição a $20 \mathrm{~mm}$ da posição inicial segundo o sentido positivo do eixo z do sistema de coordenadas, e obter nova foto de calibração. Depois de obtidas as fotos de calibração, nenhum dos dispositivos poderá sofrer qualquer movimento ou alteração de configurações, pois o processo de calibração e de processamento de imagens leva em conta uma geometria rígida e permanente, bem como uma configuração estável dos parâmetros da câmera de aquisição.

A geometria projetiva, o modelo matemático da visão natural do espaço, preconiza uma função de razão entre combinações lineares para a representação gráfica do espaço conforme a deformação natural da visão. Esta função - $\mathrm{f}_{\mathrm{Tr}}(\mathrm{X} ; \mathrm{Y})$ - aplicada a um sistema de coordenadas tem o aspecto da Equação 2.

$(x ; y)=f_{T r}(X ; Y)=\left(\frac{a X+b Y+c}{g X+h Y+i} ; \frac{d X+e Y+f}{g X+h Y+i}\right)$

Equação 2

$\mathrm{Na}$ qual,

$(\mathrm{x} ; \mathrm{y})$ : coordenadas no espaço real;

$\mathrm{X}$ e Y: coordenadas no sistema projetivo (imagem).

Os parâmetros de transformação ( $a, b, c, d, e, f, g, h, i)$ são obtidos pela relação entre os valores de $\mathrm{X}$ e $\mathrm{Y}$ do sistema projetivo e as respectivas coordenadas reais $(\mathrm{x} ; \mathrm{y})$. No processo de calibração, as coordenadas reais são conhecidas por intermédio do alvo de calibração e as coordenadas projetivas são obtidas pelo processamento das imagens de calibração. A relação entre imagem e objeto é obtida por métodos numéricos com a foto de calibração considerada num sistema de coordenadas projetivas e o alvo de calibração no sistema real de coordenadas. Com a definição da função de transformação, é possível obter a projeção das coordenadas reais de qualquer ponto no espaço, bem como determinar a posição dos pontos de vista de tomada de cena no sistema real de coordenadas. A Figura 2 contém a ilustração do dispositivo de calibração que funciona com acionamento remoto e curso do alvo atuado por sensores ópticos. Também está 


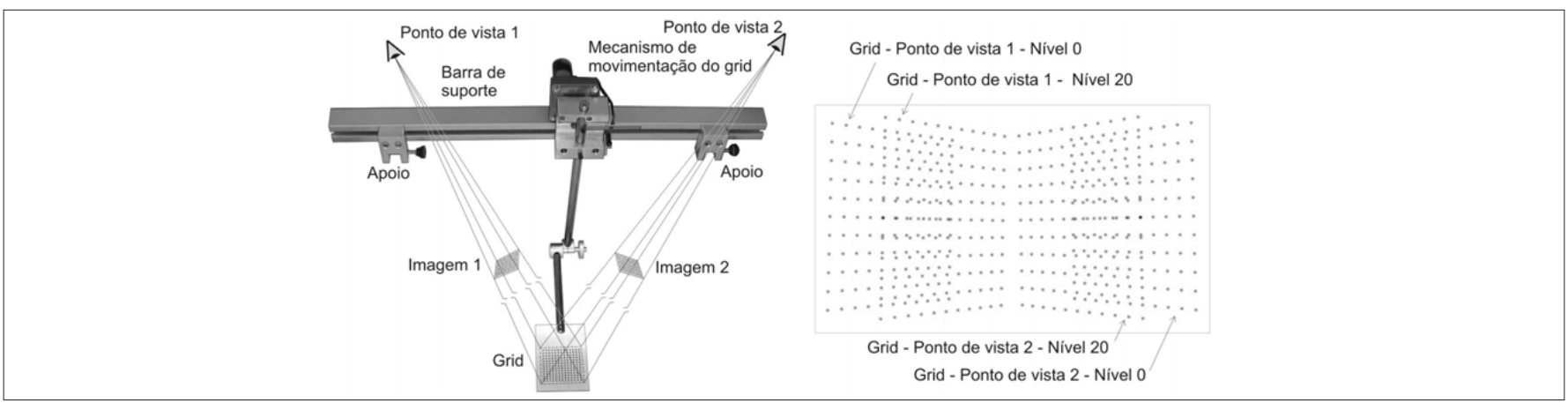

Figura 2 - Dispositivo de calibração do sistema e imagem de calibração

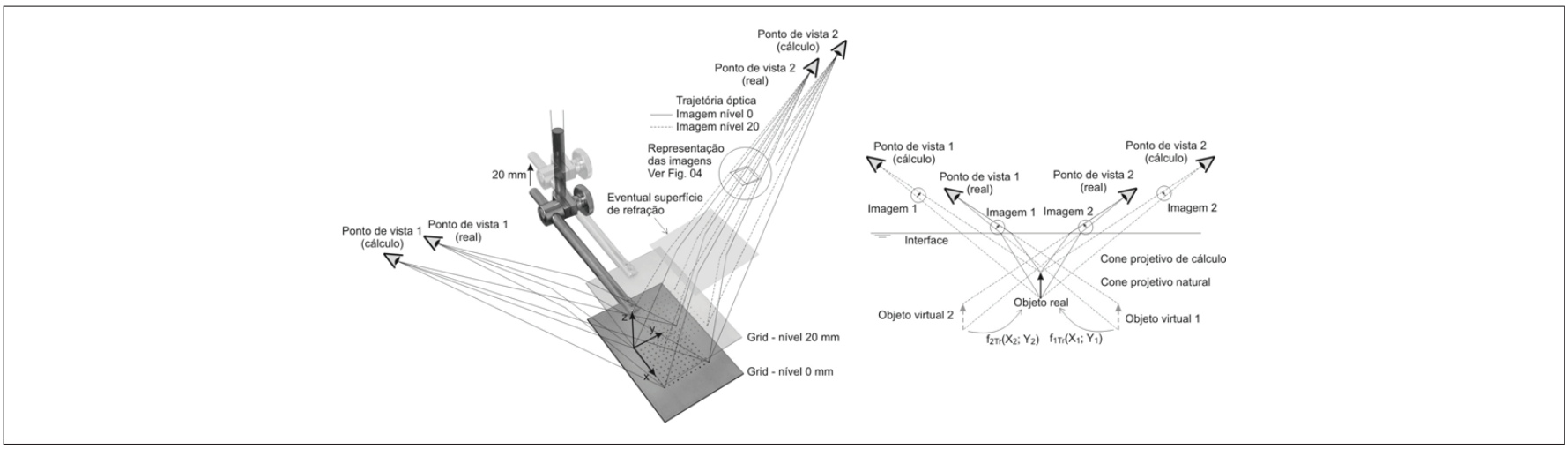

Figura 3 - Configuração genérica da calibração e demonstração esquemática da aplicação da transformação de coordenadas

ilustrada uma imagem típica de calibração com compartilhamento do quadro e sobreposição das fotos no nível 0 e no nível $20 \mathrm{~mm}$.

Na Figura 3, pode-se observar a configuração da calibração e dos pontos de vista reais e de cálculo em um sistema que envolva a aquisição de dados com trajetória óptica entre meios físicos diferentes, por exemplo, água e ar.

Para obtenção das coordenadas dos pontos de vista, é utilizado um artifício para se obter o cone projetivo com vértice no ponto de vista. A função de transformação para o nível 20 é aplicada sobre a imagem do grid de calibração na cota 0 . Com o uso da função para o nível 20, obtém-se uma projeção do nível 0 para o 20 cujo resultado conduz a pontos de grid que definem o tronco do cone (pirâmide) e, consequentemente, seu vértice.

Os deslocamentos das partículas são determinados através do algoritmo de correlação cruzada. Originalmente, este algoritmo tem uma função própria nas aplicações que envolvem processamento de imagens. Supondo que se recorte uma pequena porção de uma imagem, o algoritmo de correlação tem a função de encontrar, dentro da imagem original, a posição onde ocorreu o recorte. O algoritmo tem embasamento na aplicação da Transformada Rápida de Fourrier com comparações de intensidade atribuindo coeficientes de correlação que dependem da similaridade entre as imagens comparadas. Aplicando-se esta formulação para a velocimetria por imagens de partículas entre duas imagens sucessivas, o que se determina é um deslocamento de um quadro (área de interrogação) que, recortado

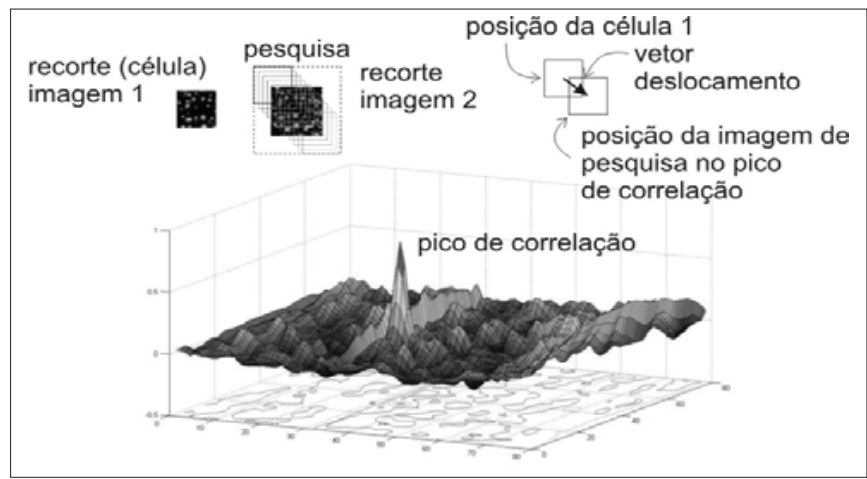

Figura 4 - Aplicação da correlação cruzada normalizada na velocimetria por imagens de partículas

da primeira imagem, melhor se encontra na segunda imagem. Como existem sensíveis diferenças entre a primeira e a segunda imagem, o algoritmo determinará a melhor aproximação retornando um coeficiente máximo (pico de correlação). As posições de recorte na primeira imagem e de coeficiente máximo na segunda imagem definem o vetor deslocamento. Este deslocamento pode fornecer resultados com, no máximo, um pixel de precisão, então é feito um cálculo adicional, o deslocamento subpixel que se estabelece através de uma interpolação pela Curva Gaussiana entre os coeficientes de correlação dos pixels vizinhos ao pixel de pico. A Figura 4 contém um esquema da aplicação do algoritmo com um gráfico que ilustra a distribuição espacial dos coeficientes de correlação cruzada. 


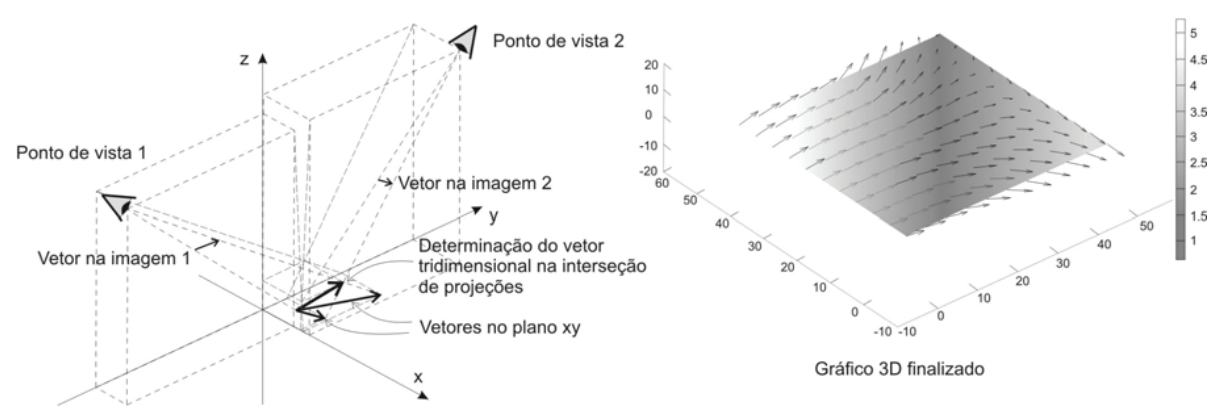

Figura 5 - Reconstituição do vetor deslocamento a partir dos campos regularizados sob os pontos de vista 1 e 2 através das interseções entre projeções

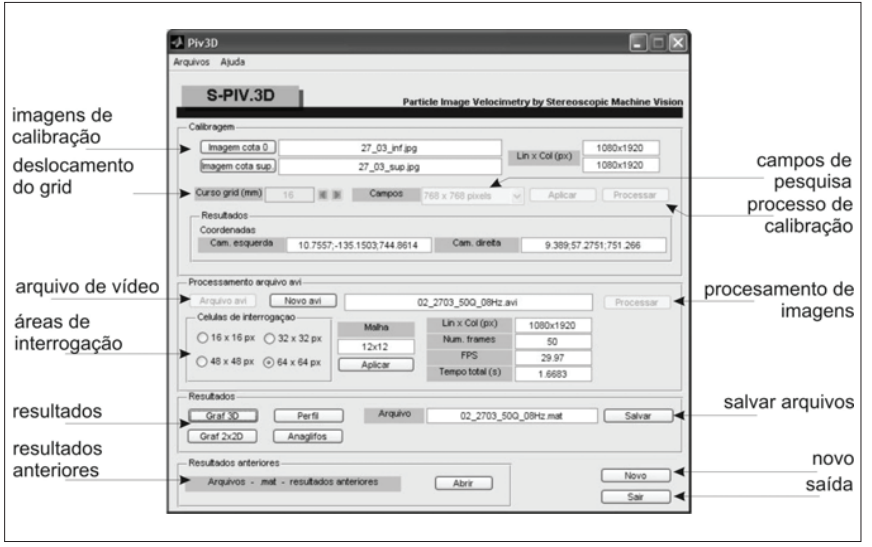

Figura 6 - Tela inicial do software S-PIV-3D

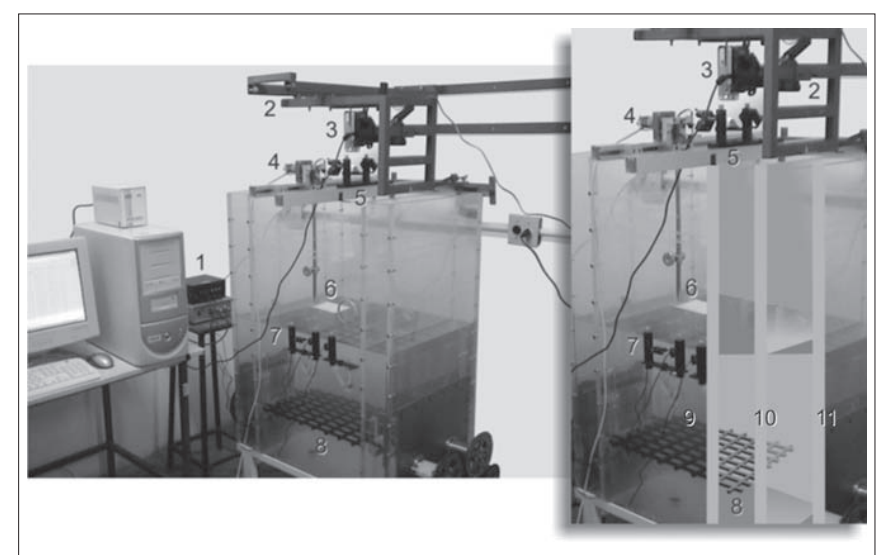

Figura 7 - Tanque de agitação por grade oscilante

As imagens tomadas sob os pontos de vista 1 e 2 são processadas e, para cada célula, é obtido um vetor deslocamento no sistema projetivo. A estes vetores, é aplicada a função de transformação de coordenadas para o nível 0 , obtendo-se vetores no sistema real de coordenadas com cota z nula. Os vetores são reagrupados por interpolação para assumirem posições regularizadas numa malha de 50 × 50 mm para cada um dos pontos de vista. Com a associação das malhas, procede-se à reconstituição dos vetores velocidade tridimensionais por meio das interseções das projeções, como pode ser observado no esquema da Figura 5.

O software S-PIV-3D contempla também requisitos para análises. Utilizando interfaces gráficas, controla uma sequência de operações que se habilitam à medida que as tarefas necessárias são cumpridas; é composto por uma janela principal e diversas outras de visualização de resultados. Ocorrem resultados gráficos que apresentam malhas de vetores, gráficos interativos, deslocamentos, médias, tendências e gráficos de visualização expandida. A Figura 6 contém a reprodução da tela inicial do programa S-PIV-3D.

Para medidas de velocidade na superfície, o sistema S-PIV-3D foi instalado sobre um tanque de ensaios com turbulência gerada por grades oscilantes. Este tipo de tanque tem a finalidade de reproduzir em laboratório a turbulência verificada nos corpos de água naturais por meio da oscilação vertical da grade instalada na parte inferior do tanque. O desenvolvimento deste equipamento baseou-se inicialmente nos estudos dos pesquisadores Thompson e Turner (1975); em seguida, foram conduzidas diversas pesquisas na Escola de Engenharia de São Carlos, citando-se o desenvolvimento do tanque de grades e a Sonda Óptica por Roma (1988), o Sistema Óptico desenvolvido por Szeliga e Roma (2004) e culminando, atualmente, no aparelhamento que se pode observar, em conjunto com a instalação do Sistema S-PIV 3D, na Figura 7. No detalhe à direita da imagem, pode-se observar uma seção do tanque onde se nota o isolamento entre a câmara central de geração de turbulência e os compartimentos laterais nos quais se produz o movimento oscilatório das grades por meio de bielas. O uso do isolamento evita que movimentos mecânicos de acionamento da grade comprometam as características da turbulência na câmara central. O tanque foi executado com partes mecânicas em aço inoxidável. (1) Fonte de alimentação para o laser; (2) Suportes ajustáveis para a câmera de aquisição; (3) Câmera de aquisição; (4) Dispositivo de calibração; (5) Estereoscópio; (6) Alvo de calibração; (7) Emissores laser; (8) Grade oscilante; (9) Parede externa frontal em acrílico; (10) Parede interna; (11) Parede externa lateral em acrílico. 
A iluminação consistiu em projetar o feixe laser rasante sobre a superfície de forma a evidenciar partículas flutuantes. As imagens resultantes são decorrentes de diversos níveis de oscilação da grade. A partir dos campos de velocidades, é possível inferir conclusões acerca da turbulência na superfície por meio de médias das componentes verticais das velocidades que, no caso desta aplicação, foram levadas em consideração por sua influência no fenômeno da reaeração. O campo de velocidades é lançado sobre uma malha contendo 121 células distribuídas num grid regular de 50 × $50 \mathrm{~mm}$. O campo de velocidades é representado pelo lançamento dos vetores sobre a malha, em cada célula, sendo possível a observação das componentes individualizadas sob qualquer ponto de vista. Uma visualização típica de resultado para a aplicação no tanque de grade oscilante pode ser observada pela reprodução de tela que consta na Figura 8.

Para análise dos resultados, foi desenvolvida uma saída gráfica no software S-PIV-3D que corresponde à visualização expandida e às médias dos módulos dos vetores verticais. As médias são apresentadas em gráficos que mostram sua variação de posição a posição.

A visualização expandida corresponde a um plano bidimensional (Posição x Tempo) de iso-superfícies de velocidades distribuídas no espaço de medição e no tempo de aquisição. As medidas de velocidades acontecem sobre as células de 5 x $5 \mathrm{~mm}$ de uma malha 50 × $50 \mathrm{~mm}$. Assim, a cada 1/30 de segundo, ocorrem 121 medições de velocidades e em ensaios com 2 segundos de duração são obtidas 7.260 medidas. Para a análise visual destes resultados, utilizou-se uma transposição das células para o eixo $\mathrm{x}$ de um plano segundo as linhas da malha e sequência de 1 a 121 . As iso-superfícies de velocidades, conforme certa convenção de cores, são plotadas sobre o plano que tem no eixo y o instante de aquisição.

\section{Resultados}

Nas Figuras 9 a 19 são apresentados resultados de ensaios realizados no tanque de grade oscilante com utilização de uma grade composta por barras espaçadas em 61,2 mm. A amplitude de oscilação da grade foi de $10 \mathrm{~cm}$ e o nível d'água no tanque foi de $54 \mathrm{~cm}$. Os resultados são apresentados através de gráficos de visualização expandida e/ou gráficos de médias com desvio padrão. Nos exemplos mostrados da Figura 9 até a Figura 19, a velocidade de oscilação da grade foi de 80 até 220 ciclos por minuto.

Na Figura 20, é apresentado um gráfico com o resumo dos resultados utilizando-se a média dos módulos das velocidades verticais e os limites relativos ao intervalo de um desvio padrão.

A obtenção do coeficiente de reaeração $\mathrm{K}_{2}$ no tanque de grade oscilante consiste num processo de desoxigenação no qual o oxigênio dissolvido é retirado do volume de água contido no tanque por meio de injeção de nitrogênio e recirculação, impondo pressão negativa por sucção. Obtidos baixos teores de oxigênio dissolvido, o volume

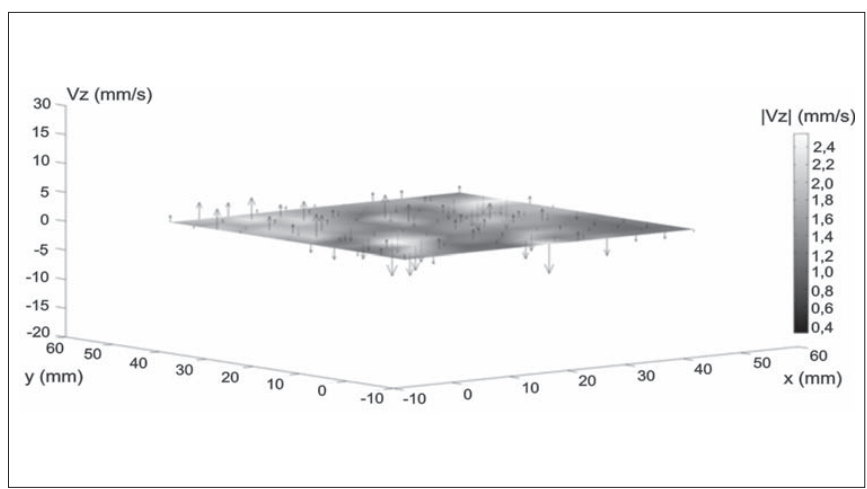

Figura 8 - Visualização típica do campo de velocidades com individualização das componentes verticais

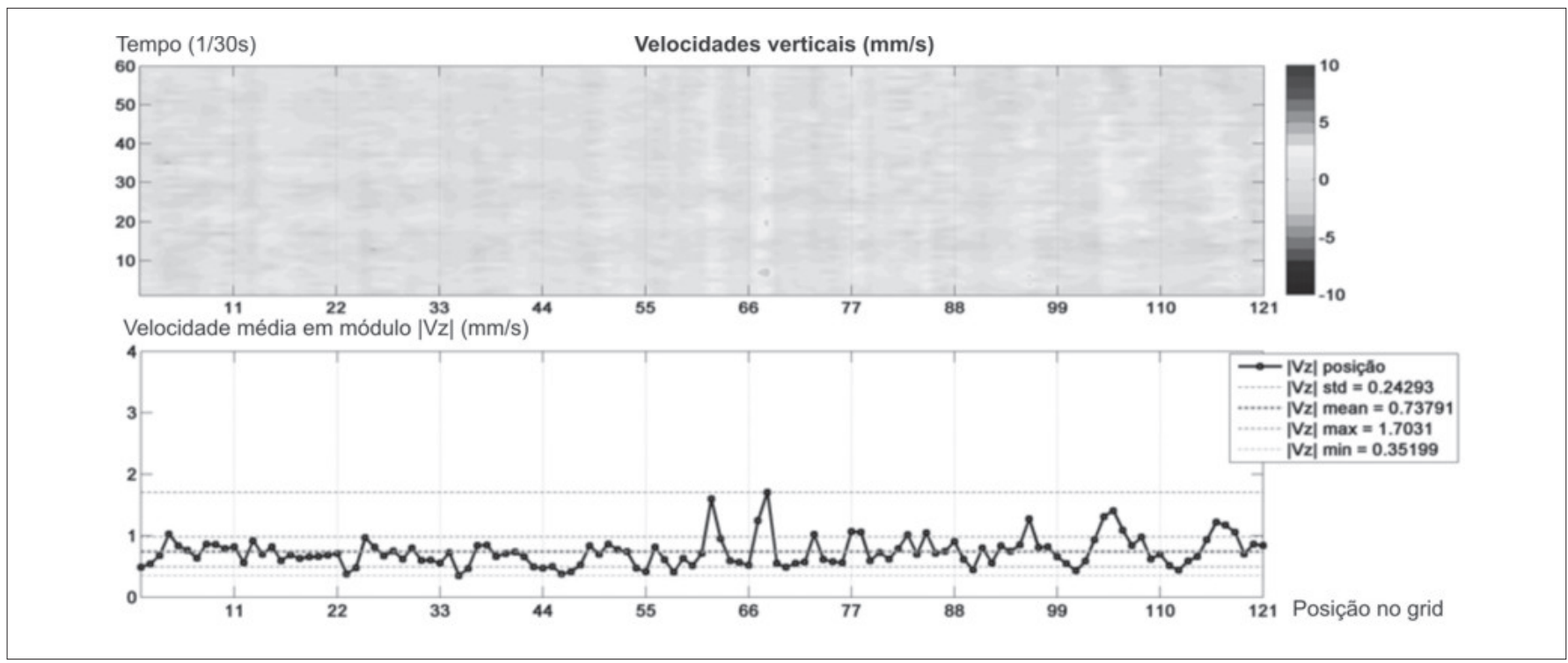

Figura 9 - Ensaio 1: velocidade de oscilação da grade, 80 ciclos por minuto 


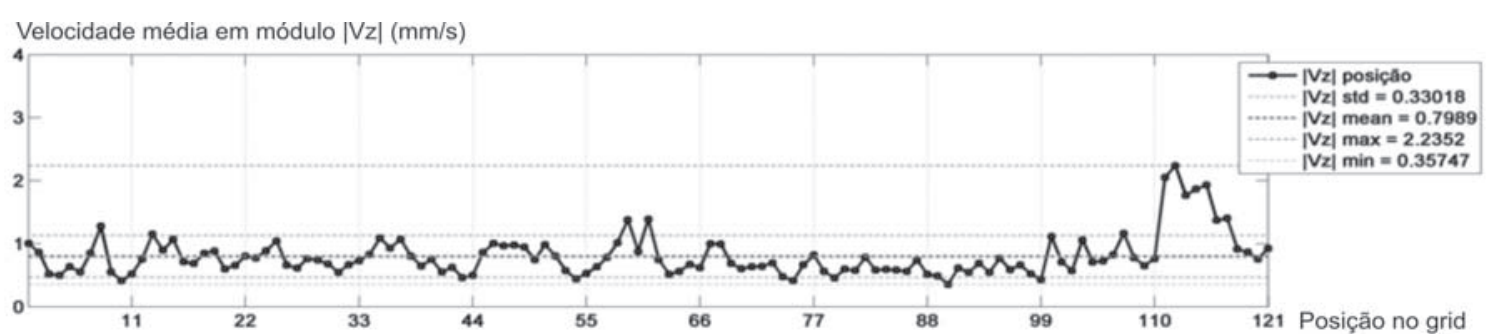

Figura 10 - Ensaio 2: velocidade de oscilação da grade, 90 ciclos por minuto

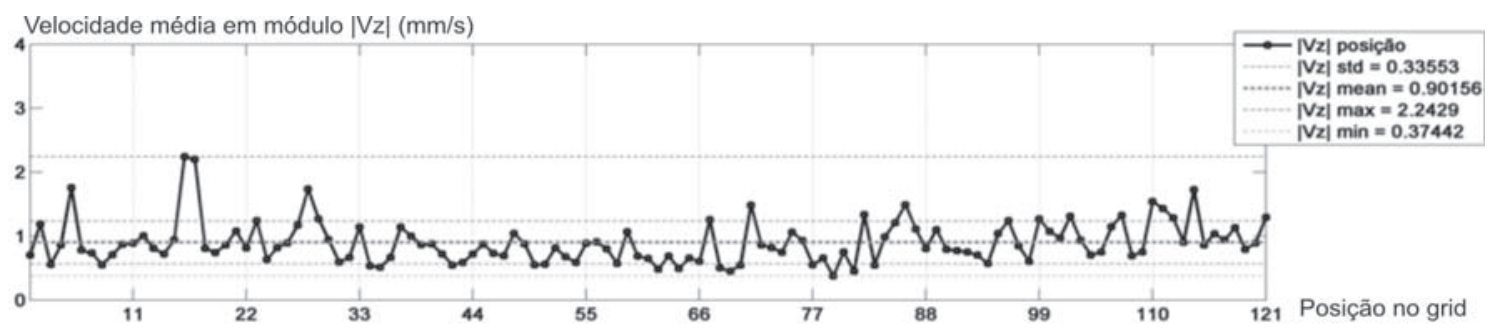

Figura 11 - Ensaio 3: velocidade de oscilação da grade, 100 ciclos por minuto

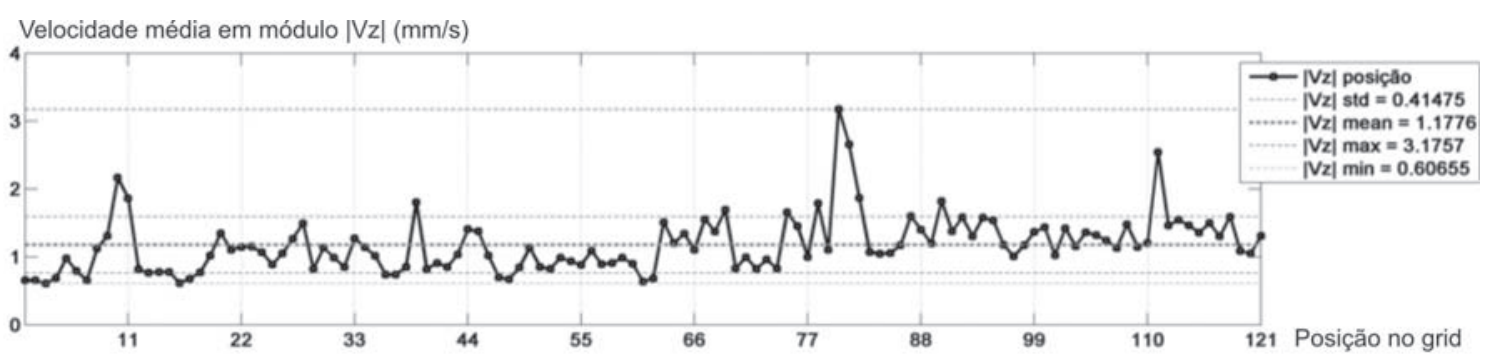

Figura 12 - Ensaio 4: velocidade de oscilação da grade, 120 ciclos por minuto

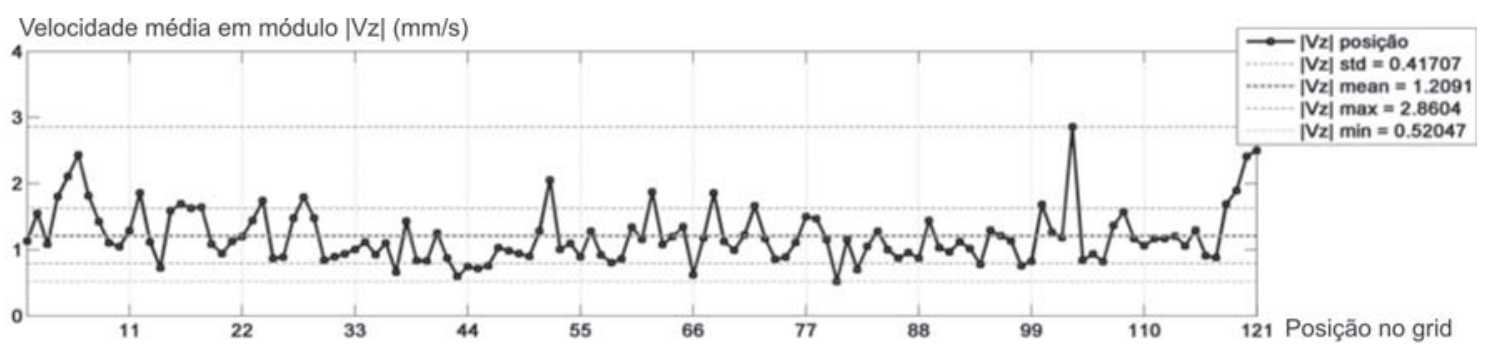

Figura 13 - Ensaio 5: velocidade de oscilação da grade, 130 ciclos por minuto

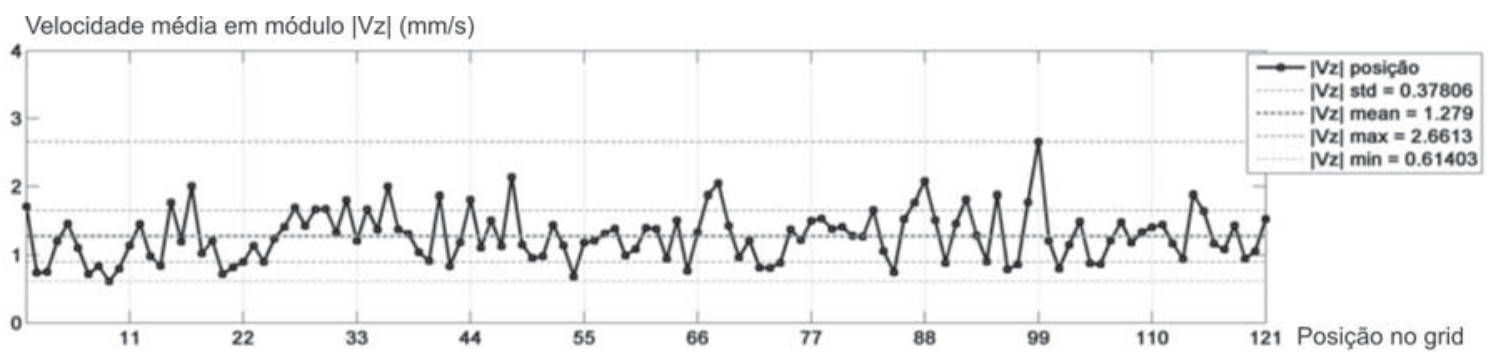

Figura 14 - Ensaio 6: velocidade de oscilação da grade, 140 ciclos por minuto 
é reoxigenado gradativamente por meio de transferência de oxigênio da atmosfera para o líquido por meio da superfície com a turbulência gerada pela oscilação da grade na região inferior do tanque. Com medidas sucessivas da concentração de oxigênio no decorrer do tempo obtém-se o coeficiente $\mathrm{K}_{2}$ pelo Método Exponencial com utilização da seguinte Equação 3.
$C=C_{S}-\left(C_{S}-C_{0}\right) e^{-K_{2} t}$

Equação 3

Na qual:

C: concentração medida no tempo t;

$\mathrm{C}_{\mathrm{S}}$ : concentração de saturação;

$\mathrm{C}_{0}$ é a concentração inicial.

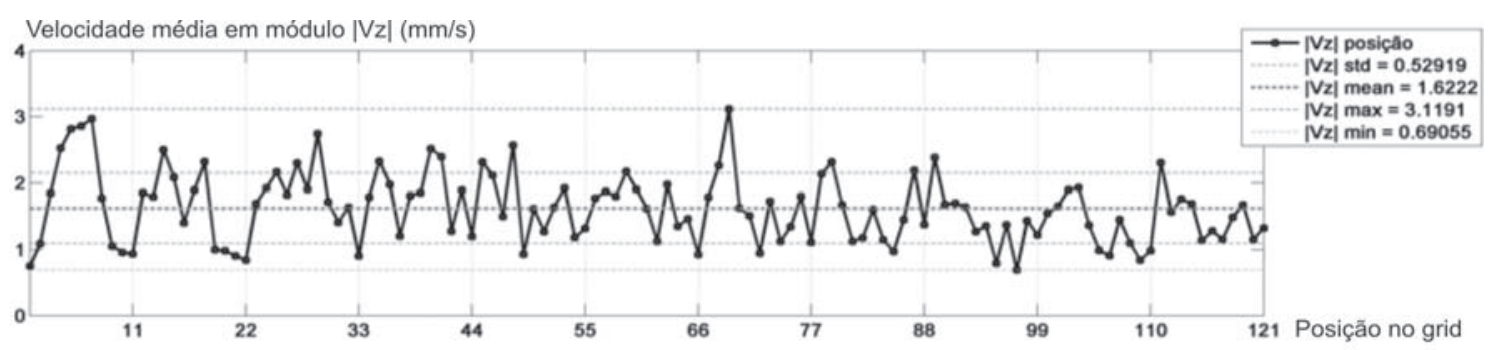

Figura 15 - Ensaio 7: velocidade de oscilação da grade, 150 ciclos por minuto

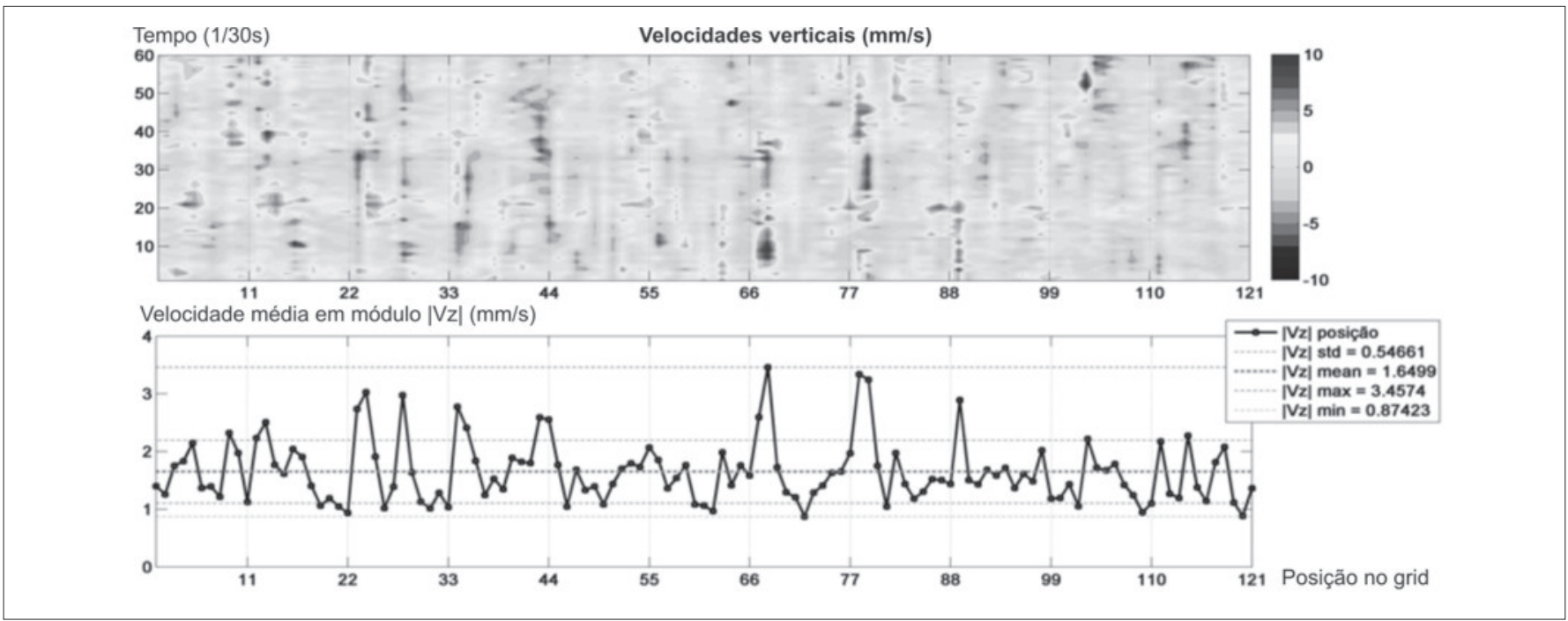

Figura 16 - Ensaio 8: velocidade de oscilação da grade, 160 ciclos por minuto

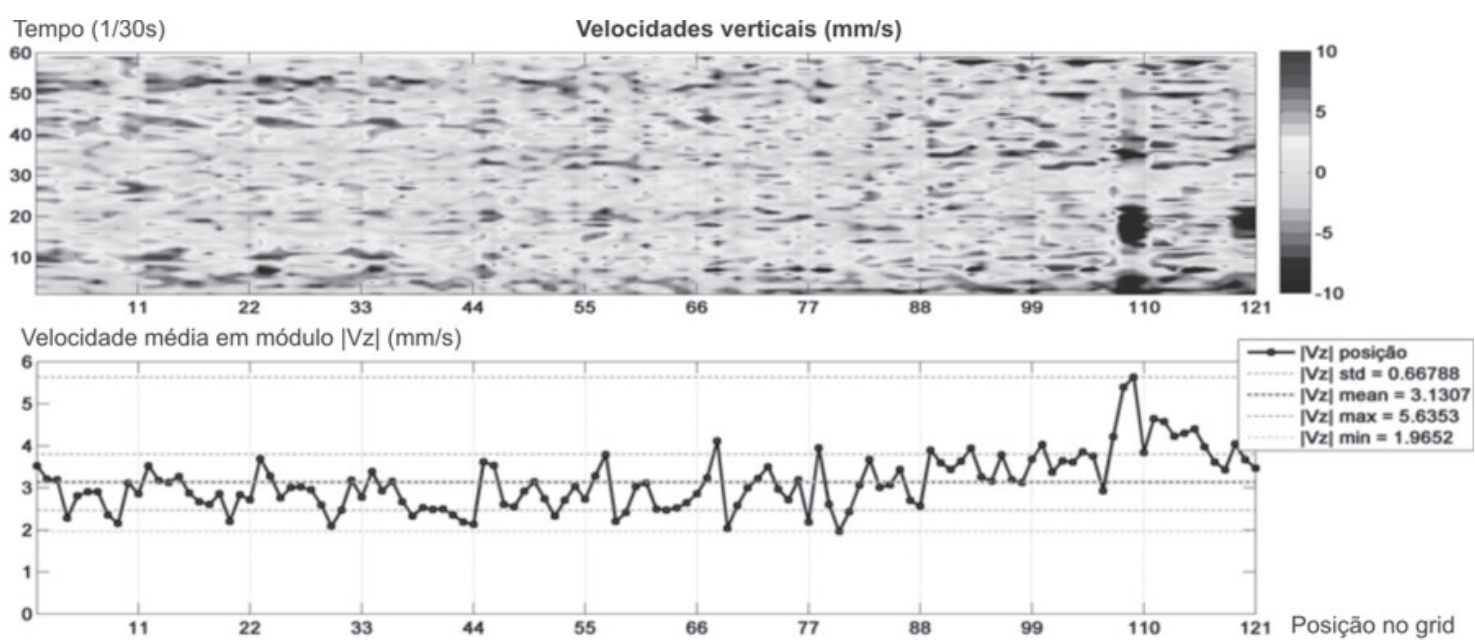

Figura 17 - Ensaio 9: velocidade de oscilação da grade, 180 ciclos por minuto 


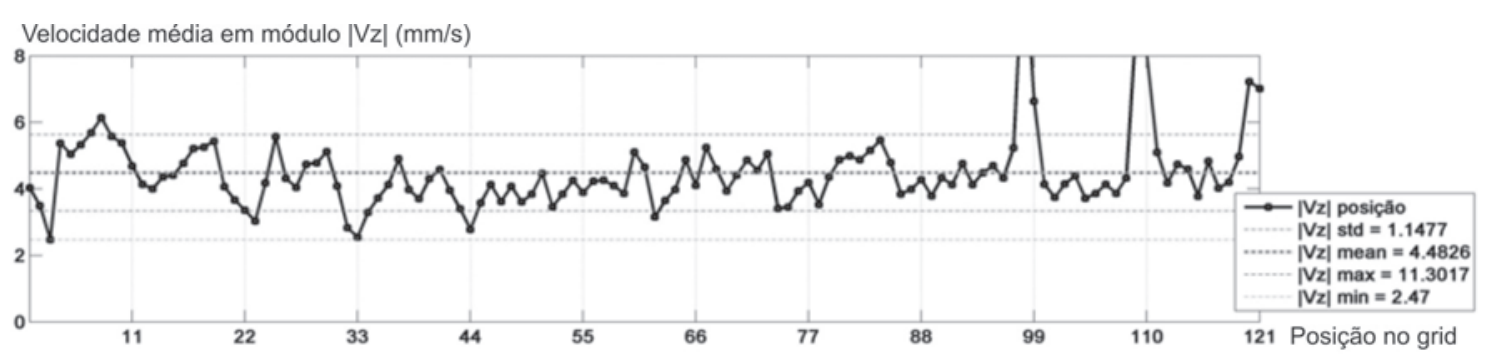

Figura 18 - Ensaio 10: velocidade de oscilação da grade, 200 ciclos por minuto

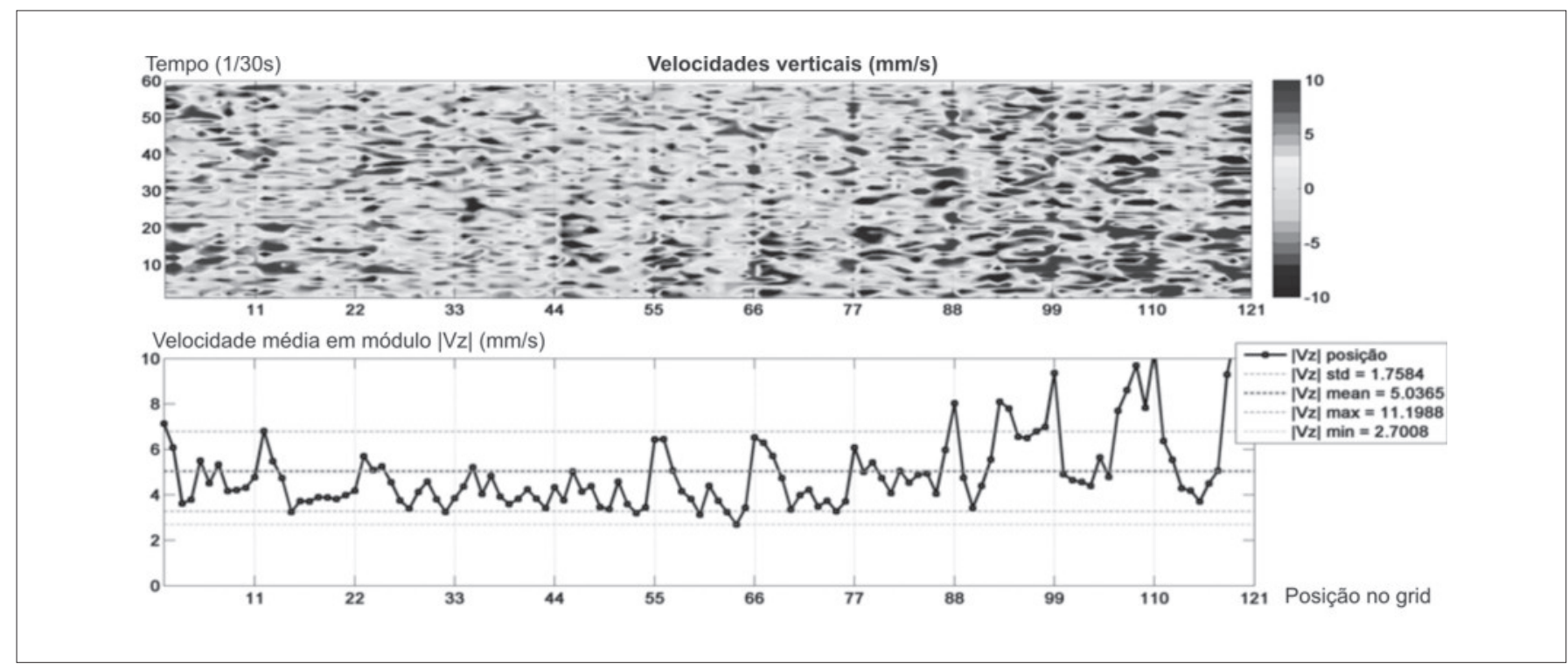

Figura 19 - Ensaio 11: velocidade de oscilação da grade, 220 ciclos por minuto

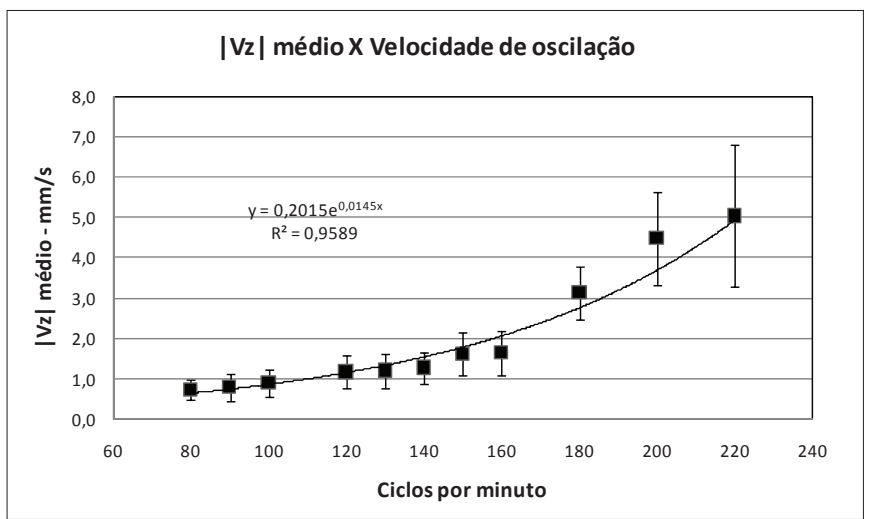

Figura 20 - Gráfico: resumo de resultados; velocidades verticais

O valor do coeficiente obtido é posteriormente corrigido para a temperatura de $25^{\circ} \mathrm{C}$. Righetto (2008) realizou ensaios para obtenção do coeficiente $\mathrm{K}_{2}$ no tanque de grade oscilante, obtendo resultados mostrados graficamente pela Figura 21.

Correlacionando-se a velocidade vertical e o coeficiente $K_{2}$ para o intervalo de oscilação da grade entre 160 e 220 ciclos por minuto, faixa de turbulência efetiva verificada no tanque de grade,

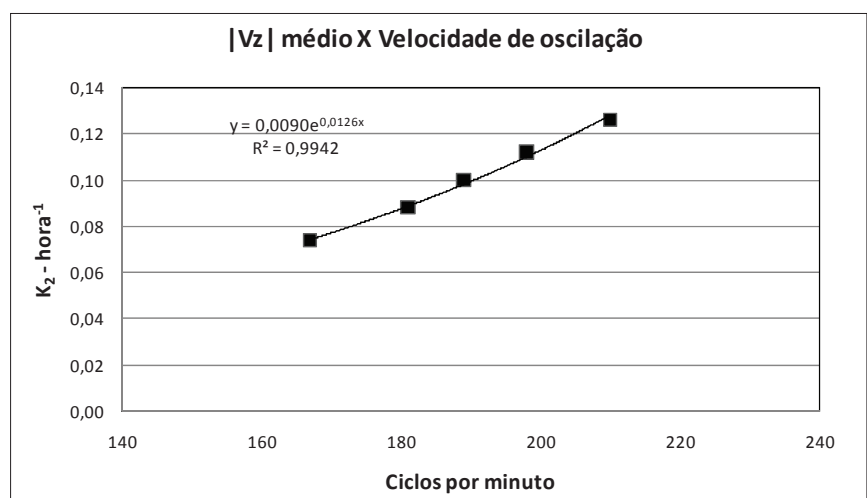

Figura 21 - Resumo de resultados: coeficientes $\mathrm{K}_{2}$

os resultados têm a configuração apresentada na Figura 22, a partir dos quais chega-se a uma equação que relaciona linearmente o Coeficiente de Reaeração $\mathrm{K}_{2}$ (1 / hora) com a velocidade vertical Vz $(\mathrm{mm} / \mathrm{s})$ na superfície de um escoamento, válida para o módulo da velocidade vertical entre $2 \mathrm{~mm} / \mathrm{s}$ e $5 \mathrm{~mm} / \mathrm{s}$ (Equação 4).

$\mathrm{K}_{2}=0,0271 \cdot \mathrm{Vz}+0,013$

Equação 4 


\section{Discussão e Conclusão}

Com relação ao método de medição empregado neste trabalho, pode-se afirmar que as características de precisão e confiabilidade dos sistemas PIV já estão consagradas em nível mundial. A tecnologia empregada no Sistema S-PIV-3D não é diferente de outros sistemas, a não ser pelas simplificações adotadas, pela acessibilidade ao software próprio, pela sua configuração adaptável às necessidades de medição e especialmente pela instalação óptica de aquisição de imagens. Assim, este sistema pode apresentar as respostas necessárias para diversas aplicações nas medições e visualizações em campos de velocidades de escoamentos, tomando partido de sua instalação relativamente simples e econômica.

O sistema PIV idealizado e empregado nessa metodologia de modelagem para a previsão do Coeficiente de Reaeração demonstrou aplicabilidade em escoamentos de baixa turbulência. Restrições ao excesso de velocidade do escoamento se estabelecem no uso de uma câmera convencional para aquisição de imagens. Este tipo de câmera tem uma capacidade de aquisição de no máximo 30 quadros por segundo.

Considerando a utilidade de previsão de capacidade de reaeração em corpos de água de baixa turbulência, a pesquisa é justificável pela importância de se preverem as influências sobre o meio ambiente, especialmente em corpos de água suscetíveis a impactos severos, como os lagos e rios de escoamento lento que têm sua autodepuração prejudicada pelas características do escoamento. A metodologia utilizada nesta pesquisa lançou mão de técnicas atuais, localizadas na fronteira da tecnologia, para medições com um objetivo bastante específico: a determinação do Coeficiente de Reaeração $\mathrm{K}_{2}$ a partir

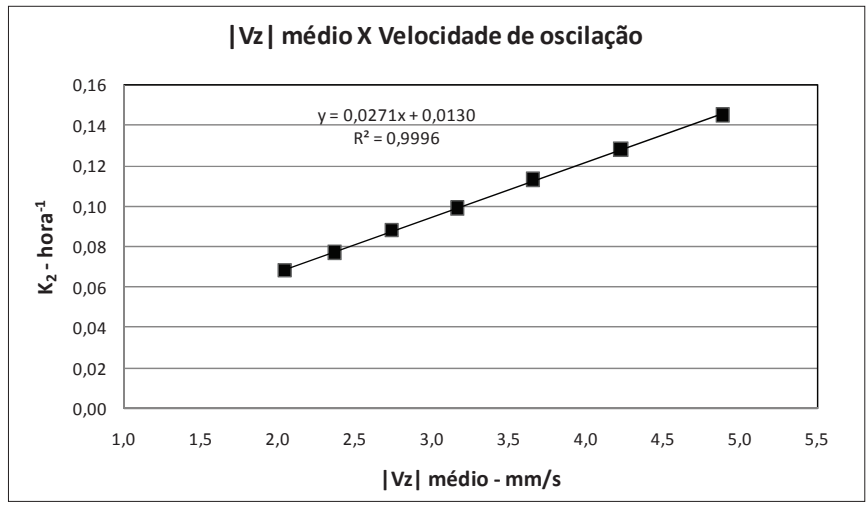

Figura 22 - Correlação: coeficientes $\mathrm{K}_{2}$ e velocidade vertical na superfície do escoamento

da medição de velocidades verticais num escoamento. Nota-se que a aplicabilidade do sistema ainda é restrita aos condicionantes proporcionados em ambiente laboratorial e sob controle de diversos mecanismos. A Equação 4 tem sua validade verificada num dispositivo mecânico: o tanque de grades oscilantes. Apesar disso, este tanque tem a premissa de reproduzir os escoamentos naturais. As validações em campo com desenvolvimento de métodos específicos deverão ser um próximo passo em pesquisas futuras para que se possa atribuir utilidade definitiva ao sistema como um todo.

\section{Agradecimentos}

Os autores reconhecem e agradecem o apoio do Conselho Nacional de Desenvolvimento Científico e Tecnológico (CNPq) ao trabalho.

\section{Referências}

ALKISLAR, B.M.; KROTHAPALLI, A.; LOURENÇO, L.M. Structure of a screeching rectangular jet: a stereoscopic particle image velocimetry study. Journal of Fluid Mechanics, v. 489, p. 121-154, 2003.

CICCA, G.M. et al. Particle image velocimetry investigation of a turbulent boundary layer manipulated by spanwise wall oscillations. Journal of Fluid Mechanics, v. 467, p 41-46, 2002.

DONG, S. et al. A combined direct numerical simulation particle image velocimetry study of the turbulent near wake. Journal of Fluid Mechanics, v. 569, p. 185-207, 2006.

GIORGETTI, M.F.; GIANSANTI, A.E. Avaliação do nível de turbulência em águas correntes e sua correlação com o coeficiente de reaeração superficial. In: $10^{\circ}$ CONGRESSO BRASILEITO DE ENGENHARIA SANITÁRIA E AMBIENTAL, 1983.

JANSEN, K.D. Flow measurements. Journal of Brazilian Society of Mechanics Science and Engineering, v. XXVI, n. 4. p. 400-419, 2004.
OKAMOTO, K. et al. Evaluation of the 3D-PIV Standard Images - PIV-STD Project. Journal of Visualization, v. 3, n. 2, p. 115-123, 2000.

PETRACCI, A. et al. Analysis of Stereoscopic PIV Measurements using Synthetic PIV Images. In: EUROPIV-2 WORKSHOP, Zaragoza, Spain, 2003

PU, Y.; MENG, H. Four-dimensional dynamic flow measurement by holographic particle image velocimetry. Applied Optics, v. 44, n. 36, p. 7697-7708, 2005

RAFFEL, M. et al. Particle image velocimetry: a pratical guide. 2 ed. New York: Ed. Springer Verlag, 2007.

RIGHETTO, M.M. Desenvolvimento e calibração de um tanque de reaeração equipado com grade oscilante. 174 f. Dissertação (Mestrado em Engenharia) - Escola de Engenharia de São Carlos, Universidade de São Paulo, São Carlos, 2008.

ROMA, W.N.L. Medida dos parâmetros de turbulência superficial e sua 
interrelação com o coeficiente de reaeração. 74 f. Tese (Livre Docência) - Escola de Engenharia de São Carlos, Universidade de São Paulo, São Carlos, 1988.

ROUSE, H.; DODU, I. Diffusion turbulent a travers une descontinuite de densite. La Houille Blanche, v.10, p. 522-581, 1955.

SENGUPTA, T.K. et al. Accelerated flow past a symmetric aerofoil: experiments and computations. Journal of Fluid Mechanics, v. 591, p. 255-288, 2007.

SMITH, B.L.; GLEZER, A. Jet vectoring using synthetic jets. Journal of Fluid Mechanics, v. 458, p. 1-34, 2002.

SZELIGA, M.R.; ROMA, W.N.L. Sistema de visão computacional para medição de turbulência e correlação com a reaeração de corpos d'água receptores. Engenharia Sanitária e Ambiental, v. 9, n. 1, p. 30-44, 2004.
TAO, B.; KATZ, J.; MENEVEAU, C.C. Statistical geometry of subgridscale stresses determined from holographic particle image velocimetry measurements. Journal of Fluid Mechanics, v. 457, p. 35-78, 2002.

THOMPSON, J.S.; TURNER, J.S. Mixing across an interface due to turbulence generated by an oscillating grid. Journal of Fluid Mechanics, v. 67, p. $349-368,1975$.

URBAN, W.D.; MUNGAL, M.G. Planar velocity measurements in compressible mixing layers. Journal of Fluid Mechanics, v. 431, p. 189222, 2001.

YANG, Y.; ROCKWELL, D. Wave interaction with a vertical cylinder: spanwise flow patterns and loading. Journal of Fluid Mechanics, v. 460, p. 93-129, 2002. 